\title{
Effect of treatment with a mixture of bacteria and fibrolytic enzymes on the quality and safety of corn silage infested with different levels of rust
}

\author{
O. C. M. Queiroz, S. C. Kim, ${ }^{1}$ and A. T. Adesogan ${ }^{2}$ \\ Department of Animal Sciences, Institute of Food and Agricultural Sciences, University of Florida, Gainesville 32608
}

\begin{abstract}
This project aimed to determine if a dual-purpose bacterial inoculant could mitigate potential adverse effects of increasing levels of rust infestation on the quality, aerobic stability, and safety of corn silage. Corn plants with no rust infestation (NR), or medium (all leaves on the lower half of the plant affected, MR), or high (all leaves affected, HR) levels of southern rust infestation were harvested at random locations on a field, chopped, and ensiled without (control, CON) or with a dual-purpose inoculant applied at a rate that supplied $1 \times 10^{5} \mathrm{cfu} / \mathrm{g}$ of Pediococcus pentosaceus 12455 and $4 \times 10^{5} \mathrm{cfu} / \mathrm{g}$ of Lactobacillus buchneri 40788 . Each treatment was prepared in quadruplicate in $20-\mathrm{L}$ mini silos and ensiled for $97 \mathrm{~d}$. As the level of rust infestation increased, the concentrations of dry matter (DM) and neutral detergent fiber increased, whereas DM digestibility decreased by up to $16 \%$. Control HR silages also had lower 24-h neutral detergent fiber digestibility (NDFD; $36.2 \%$ of DM) than CON MR (39.8\%) or NR silages $(38.1 \%)$. Inoculation increased the NDFD of NR (43.4\%) and MR silages (45.7\%) but not HR silages $(33.0 \%)$. Concentrations of lactate and volatile fatty acids decreased with increasing rust infestation in CON silages, but this trend was absent in inoculated silages. In HR silages, inoculation increased aerobic stability by $75 \%$ ( 77.3 vs. $44 \mathrm{~h})$, and prevented production of aflatoxin (5.2 vs. $0 \mathrm{mg} / \mathrm{kg}$ ). The concentration of aflatoxin in uninoculated HR silages exceeded action levels stipulated by the US Food and Drug Administration. In conclusion, increasing rust infestation was associated with reductions in the nutritive value and fermentation of corn silage. Inoculation reduced adverse effects of rust infestation on the fermentation, increased 24-h NDFD of NR and MR silages, and decreased aerobic spoilage and aflatoxin production in HR silages.
\end{abstract}

Received February 13, 2012.

Accepted April 27, 2012.

${ }^{1}$ Current address: Department of Animal Science (Institute of Agricultural and Life Science), Gyeongsang National University, Jinju, South Korea.

${ }^{2}$ Corresponding author: adesogan@ufl.edu
Key words: southern rust, silage inoculant, aflatoxin, corn silage

\section{INTRODUCTION}

Southern corn rust is an aggressive disease of corn caused by Puccinia polysora Underw. Pustules produced during the growth of the fungus cause severe damage to the leaf cuticle resulting in increased transpiration, premature leaf desiccation, and reduced photosynthesis and nutrient translocation (Lucas, 1998). The fungus can kill the hosts and cause yield losses of up to $45 \%$ as previously reported in cases of severe epiphytotic contamination in the United States (Rodriguez-Ardon et al., 1980) and other areas of the world (Rhind et al., 1952; Liu and Wang, 1999). The disease has several similar symptoms and effects to common rust, which is caused by Puccinia sorghi; however, cool wet conditions favor common rust, whereas hot humid conditions favor southern rust. Furthermore, southern rust has been reported to be the most destructive of the rusts that occur on corn worldwide (Raid et al., 1988) and it has caused yield loss as far north as Central Pennsylvania (Johnson et al., 1997). Despite the existence of resistant commercial corn hybrids, the unpredictable occurrence of Southern rust and its fast and aggressive development make it a real threat to dairy operations in the Southeast that feed corn silage.

Infestation of corn plants by Puccinia polysora can negatively affect the chemical composition of corn forage. Johnson et al. (1997) reported increases in concentrations of DM, NDF, and ADF and a decrease in DM digestibility of corn forage infested by southern rust. These effects partly reflect the fact that after infecting plants, Puccinia spp. rapidly convert photosynthates such as glucose and fructose into other fungus-specific products such as alcohols (Manners et al., 1982). Loss of such photosynthates, which are critical fermentation substrates, may inhibit or delay the acidification necessary for proper forage preservation during ensiling. Because many of the fermentation-inhibiting bacteria and spoilage-causing fungi thrive at high $\mathrm{pH}$ values (4.5 to 6; McDonald et al., 1991), delayed acidification due to rust infestation could potentially predispose silage 
to poor nutritional value, spoilage, and mycotoxin contamination (González Pereyra et al., 2008; Pedroso et al., 2010).

Pediococcus pentosaceus is a homolactic bacterium that often is used as a silage inoculant. Unlike Lactobacillus plantarum, $P$. pentosaceus can rapidly dominate the initial stages of the fermentation, when silage $\mathrm{pH}$ is between 6.5 and 5 and residual oxygen is still present (McDonald et al., 1991; Kung et al., 2003). Lactobacillus buchneri is a commonly used heterofermentative bacteria in silage inoculants because it converts lactic acid to acetic acid and thereby increases silage aerobic stability (Oude Elferink et al., 2001). To our knowledge, no study has evaluated if such inoculants can improve the quality and safety of disease-infested silage. Yet the safety of feeding silage to animals depends on the mold population, which can contaminate silage with harmful mycotoxins (Mallmann et al., 2009).

This study aimed to examine if bacterial inoculation could mitigate potential adverse effects of southern rust infestation on the fermentation, nutritive value, aerobic stability, and safety of corn silage. We hypothesized that rust infestation would decrease the quality of corn silage and inoculation would mitigate adverse effects of the disease on measures of silage quality and safety.

\section{MATERIALS AND METHODS}

\section{Silage, Treatments, and Design}

A corn hybrid (DeKalb 69-70; Monsanto Co., St. Louis, MO) was grown on a 65-ha field in August 2007 in Hague, FL as a summer silage crop. The corn was infested with southern rust at tasselling and treated with Abound fungicide (Syngenta Crop Protection LLC, Greensboro, NC) by aerial application using a crop duster airplane. Uneven coverage of the fungicide allowed rust to persist in some parts of the field. Consequently, in some areas, plants were completely disease free (no rust, NR) whereas in other areas, leaves in the lower half (medium rust, MR) or all leaves (high rust, HR; Figure 1) had the yellowish brown discoloration and dense occurrence of small orange pustules that typify the disease. Corn forage from representative parts of the field with each rust classification were harvested when the DM concentration of NR plants was $40 \%$ and chopped using a Jaguar 900 forage harvester (Claas of America Inc., Omaha, NE). The forages were placed in separate piles and either treated with $100 \mathrm{~mL}$ of deionized water (control, CON) or $100 \mathrm{~mL}$ of a solution of Buchneri 500 inoculant (INOC, LB500; Lallemand Animal Nutrition, Milwaukee, WI). As specified by the manufacturer, the inoculation rate delivered $1 \times 10^{5}$ $\mathrm{cfu} / \mathrm{g}$ of Pediococcus pentosaceus 12455 and $4 \times 10^{5}$ cfu/g of Lactobacillus buchneri 40788 and it also contained enzymes resulting from Trichoderma reesei fermentation. Manufacturer-stipulated minimum activities were $400 \mathrm{mg}$ of glucose/min per gram ( $\beta$-glucanase), $1.140 \mathrm{mg}$ of glucose/min per gram (xylanase), and 18 $\mathrm{mg}$ of glucose/min per gram (galactomannanase). Four replicates of each treatment were ensiled in 20-L plastic bucket silos at a density of $250 \mathrm{~kg}$ of $\mathrm{DM} / \mathrm{m}^{3}$ for $97 \mathrm{~d}$ at ambient temperature $\left(25^{\circ} \mathrm{C}\right)$ in an enclosed barn. The sequence of harvest and ensiling was as follows: NR, MR, and HR. Each of the 24 silos was sealed with airtight plastic lids secured with heavy-duty duct tape. Samples of freshly treated forage were stored at $-20^{\circ} \mathrm{C}$ for chemical analyses. Weights of empty and full silos at ensiling were recorded for estimation of DM loss. At silo opening, the forage was transferred to a plastic bag for proper mixing, after which subsamples were collected for analysis of nutritive value, microbial counts, aerobic stability, and mycotoxins.

\section{Laboratory Analysis}

Corn forage and silage samples were dried at $60^{\circ} \mathrm{C}$ for $48 \mathrm{~h}$ in a forced-air oven. Dried samples were ground to pass the 1-mm screen of a Wiley mill (A. H. Thomas Co., Philadelphia, PA) and analyzed for DM $\left(105^{\circ} \mathrm{C}\right.$ for $16 \mathrm{~h})$ and ash $\left(512^{\circ} \mathrm{C}\right.$ for $\left.8 \mathrm{~h}\right)$. Concentrations of NDF and ADF were measured in an ANKOM 200 fiber analyzer (Ankom Technology Corp., Macedon, NY) using the method of Van Soest et al. (1991). Heatstable $\alpha$-amylase and sulfite were used in the NDF assay. Nitrogen was determined by rapid combustion using a macro elemental $\mathrm{N}$ analyzer (vario MAX CN, model ID 25.00-5003; Elementar Analysensysteme GmbH, Hanau, Germany) and CP was calculated by multiplying $\mathrm{N}$ concentration by a factor of 6.25 . In vitro true DM digestibility (IVTDMD) was measured with the method of Van Soest et al. (1966) and NDF digestibility (NDFD) was estimated after analysis of dried samples and residues from the IVTDMD assay for NDF. Ammonia-N was measured by distillation (AOAC, 1985). Silage samples were also analyzed for aflatoxin, zearalenone, deoxynivalenol, and fumonisin by thin-layer chromatography (Scott et al., 1970) at Dairyland Laboratories Inc., Arcadia, WI).

Silage extract was prepared within $3 \mathrm{~h}$ of harvesting by mixing $25 \mathrm{~g}$ of corn silage with $225 \mathrm{~mL}$ of $0.1 \%$ peptone water in a stomacher for $3 \mathrm{~min}$. The solution was filtered through 2 layers of cheesecloth and an aliquot was immediately used for fungal counts as described by Schmidt and Kung (2010). Yeasts and molds were enumerated after serial 10-fold dilutions by spread plating on malt extract agar (Oxoid CM59; Oxoid Inc., Basingstoke, UK). Silage $\mathrm{pH}$ was measured using a $\mathrm{pH}$ meter 

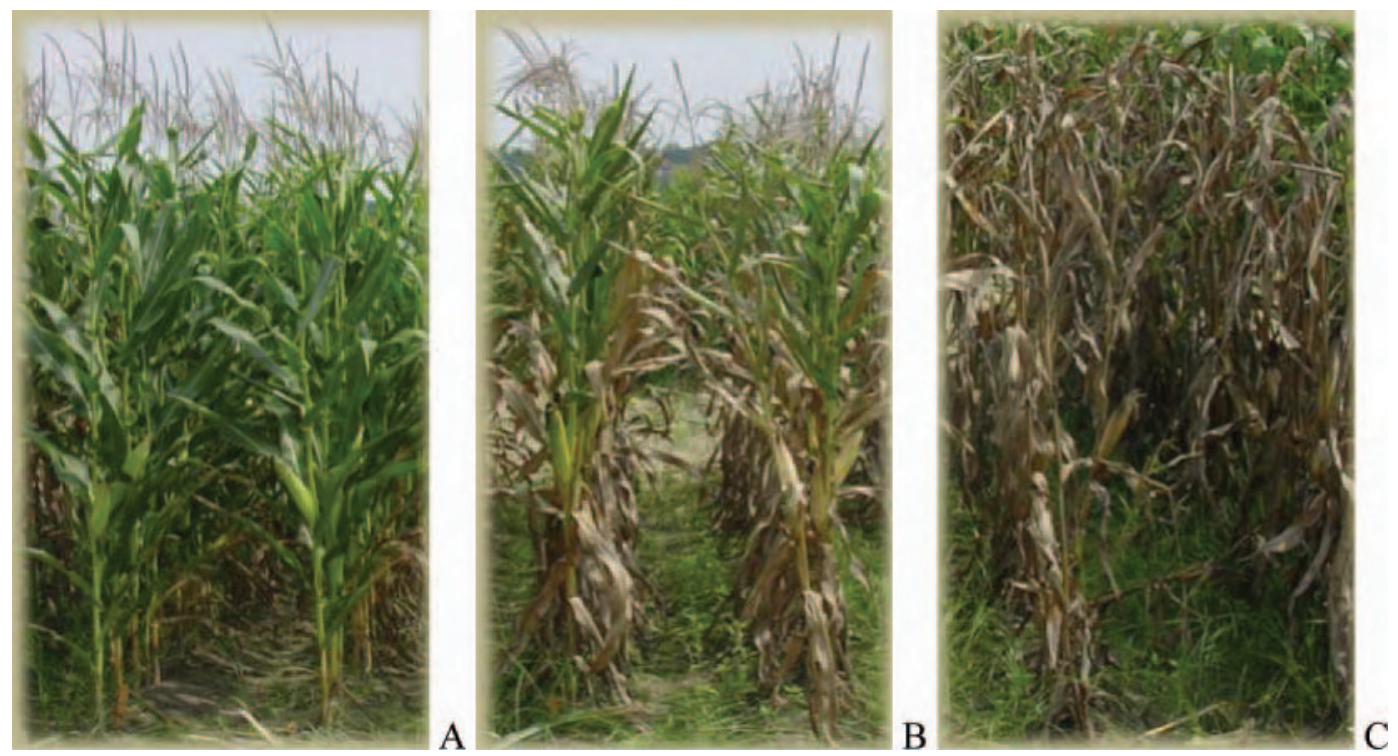

Figure 1. Corn plants affected by different severities of southern rust. (A) No rust, (B) medium rust, and (C) high rust. Color version available in the online PDF.

(Corning model 12; Corning Scientific Instruments, Medfield, MA). An aliquot of $100 \mathrm{~mL}$ of silage extract was stored at $-20^{\circ} \mathrm{C}$, after its $\mathrm{pH}$ was reduced to 2 with $50 \%$ (wt/vol) sulfuric acid. Subsequently, such samples were used to quantify lactate and VFA with a highperformance liquid chromatograph (FL 7485; Hitachi Ltd., Tokyo, Japan) coupled to a UV detector (Spectroflow 757; ABI Analytical Kratos Division, Ramsey, NJ) set at $210 \mathrm{~nm}$. The column was a Bio-Rad Aminex HPX-87H (Bio-Rad Laboratories Inc., Hercules, CA) with a $0.015 M$ sulfuric acid mobile phase and a flow rate of $0.7 \mathrm{~mL} / \mathrm{min}$ at $45^{\circ} \mathrm{C}$ (Arriola et al., 2011).

Aerobic stability was measured by placing $2 \mathrm{~kg}$ of silage in an open-top polystyrene box. Temperature sensors (Hobo temperature data logger 64k; Onset Computer Corp., Cape Cod, MA) were placed in the geometric center of each silage sample and temperatures were recorded every $30 \mathrm{~min}$ for $14 \mathrm{~d}$. Four additional sensors were placed in the room to record ambient temperature. Silages were covered with 2 layers of cheesecloth to avoid drying. Aerobic stability was denoted by the time that elapsed before the difference between silage and ambient temperature was above $2^{\circ} \mathrm{C}$ (Huisden et al., 2009). Samples of corn forage also were analyzed for DM, CP, NDF, ADF, IVTDMD, 24-h NDFD, aflatoxin, zearalenone, deoxynivalenol, and fumonisin as described above.

\section{Statistical Analysis}

This experiment was analyzed as a completely randomized design with a 3 (severity of rust: NR, MR, and
$\mathrm{HR}) \times 2$ (inoculation treatments: INOC vs. CON) factorial arrangement of treatments. The GLM procedure of SAS (version 9.2; SAS Institute Inc., Cary, NC) and a model containing inoculant, rust, and interactions of these terms, was used to analyze the data. Mean separation was performed using the PDIFF procedure of SAS, which uses the Fisher F-protected least significant difference test. Polynomial contrasts were used to examine effects of rust, inoculant, and the interaction. Significance was declared at $P \leq 0.05$ and tendencies at $0.1 \geq P>0.05$.

\section{RESULTS AND DISCUSSION}

The chemical composition of the freshly treated corn forage (Table 1) was similar to that of corn forage in other studies in Florida (Kim and Adesogan, 2006; Huisden et al., 2009) except that concentrations of NDF and ADF of MR and HR silages were greater. The chemical composition, IVTDMD, and NDFD of silages are shown in Table 2. For reasons that are unclear, the NDF and ADF concentration of the inoculated HR silages were greater than those of the control HR silages. Increasing rust infestation increased $(P<0.001$, quadratic) the DM concentration of the silages and resulted in a 20-percentage-unit difference between NR and HR silages. Crude protein and ash concentrations decreased to a nadir in MR silage and then increased $(P<0.001$, quadratic) with increasing rust infestation. The NDF and ADF concentrations increased linearly $(P<0.01)$, whereas IVTDMD decreased linearly $(P<$ $0.001)$ as rust infestation increased. The decreases in 
Table 1. Chemical composition (means $\pm \mathrm{SD}$ ) of untreated and inoculated corn forage with different levels of rust infestation (\% of DM) ${ }^{1}$

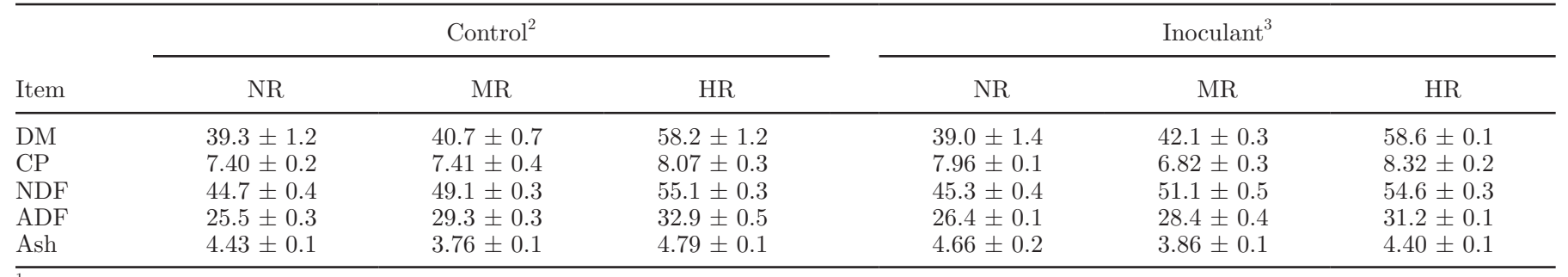

${ }^{1} \mathrm{NR}=$ no-rust level; $\mathrm{MR}=$ medium rust level; $\mathrm{HR}=$ high rust level.

${ }^{2}$ Control $=$ no inoculant added.

${ }^{3}$ Inoculant $=1 \times 10^{5}$ cfu of Pediococcus pentosaceus and $4 \times 10^{5}$ of Lactobacillus buchneri.

the nutritive value of corn silage with increasing rust infestation reflect the effects of the disease on corn forage (Johnson et al., 1997) and indicate that ensiling did not mitigate adverse effects of rust infestation on silage nutritive value. Puccinia polysora induces a premature desiccation of the plant (Rodriguez-Ardon et al., 1980), which could explain the adverse effects of increasing rust infestation on forage and silage DM concentration and nutritive value in this study. Johnson et al. (1997) reported that the DM, NDF, and $\mathrm{ADF}$ concentrations of 5 corn hybrids were increased by southern rust infestation, leading to decreased IVTDMD. Potter (1987) and Wilson et al. (1991) reported that rust infestation decreased the digestibility of 2 cultivars of ryegrass and pearl millet, respectively. In agreement, this study shows that rust infestation decreased the digestibility of corn forage and silage, largely by increasing the relative proportion of fiber in the silage. Others have reported that the lower digestibility reflects increased lignin deposition (Hammerschmidt, 1984), which is a defense mechanism against the invading fungus and the associated disease (Ride, 1978).

Johnson et al. (1997) reported that rust infestation had no effect on the CP concentration of corn plants.
Although a quadratic CP response to increasing rust infestation was detected in this study, the differences in $\mathrm{CP}$ concentration were very small. Based upon a literature review, Dimmock and Gooding (2002) stated that the effect of rust on wheat protein is variable even though rust may have a deleterious effect on $\mathrm{N}$ accumulation and partitioning within the plant.

Inoculation slightly reduced $(P<0.001)$ the DM concentration and increased $(P=0.02)$ the ADF concentration of silages, perhaps reflecting the use of water-soluble carbohydrates as substrates by the bacteria in the inoculant. Inoculation also increased the NDFD of silages of NR and MR silages (inoculant $x$ rust interaction, $P=0.0004$ ), probably reflecting the action of the fibrolytic enzymes in the inoculant as well as those that may have been released by L. buchneri (Kang et al., 2009). The absence of this effect in the HR silage is likely attributable to lack of sufficient moisture for enzyme action.

All silages had $\mathrm{pH}$ equal to or less than 4, indicating that the fermentations were satisfactory (Table 3). However, increasing rust infestation increased the $\mathrm{pH}$ values (quadratic, $P<0.001$ ). The latter occurred largely because in CON forages, increasing rust infesta-

Table 2. Effect of rust infestation level and inoculant application on chemical composition of corn silage (\% of DM or as stated $)^{1}$

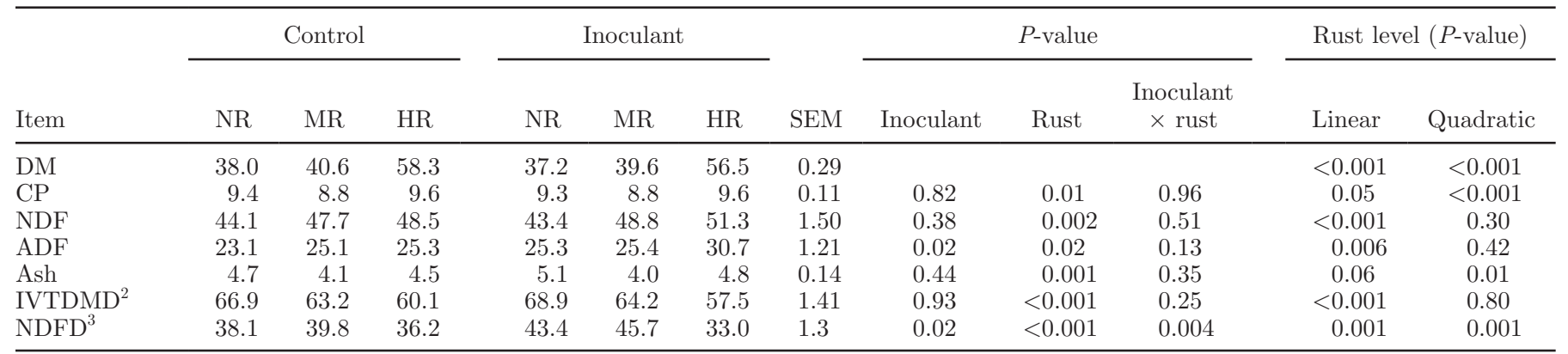

${ }^{1}$ Control $=$ no inoculant added; inoculant $=1 \times 10^{5}$ cfu of Pediococcus pentosaceus and $4 \times 10^{5}$ of Lactobacillus buchneri; NR $=$ no-rust level; $\mathrm{MR}=$ medium rust level; HR = high rust level.

${ }^{2}$ IVTDMD $=48$-h in vitro true DM digestibility $(\%)$.

${ }^{3} \mathrm{NDFD}=\mathrm{NDF}$ digestibility obtained after 48-h incubation in ruminal fluid (\%). 
tion progressively decreased concentrations of lactate, acetate, propionate, and total VFA, whereas these trends were mostly reversed by INOC (rust $x$ inoculant interaction, $P<0.01$ ). These results demonstrate that rust infestation worsens the fermentation of corn silage but INOC can mitigate such effects. It is also noteworthy that INOC was most effective at improving the fermentation of HR silages.

In CON silages, ammonia- $\mathrm{N}$ concentrations decreased to a nadir in MR silages as rust infestation increased but they increased progressively in INOC silages (rust $\times$ inoculant interaction, $P<0.001$ ). Butyrate was only detected in HR silages and CON HR silages had less $(P=0.023)$ butyrate than INOC HR silages. These results suggest that secondary clostridial fermentation occurred in HR silages (McDonald et al., 1991), but it was inhibited at least partly by INOC.

Yeasts were not detected in the silages and INOC did not affect DM losses. Mold counts decreased (quadratic, $P<0.05)$ as the level of rust infestation increased likely because of the concomitant increases in DM concentration reduced the water activity of the silages. Aerobic stability increased (quadratic, $P<0.01$ ) as the level of rust infestation increased, reflecting the corresponding decrease in mold counts. Inoculation had no effect $(P$ $=0.13$ ) on mean mold counts, although counts were 3.5 times greater in CON HR than in INOC HR silages (3.40 vs. $0.95 \mathrm{cfu} / \mathrm{g})$. The latter explains the $75 \% \mathrm{im}-$ provement in the aerobic stability of CON compared with INOC HR silages (44 vs. $77 \mathrm{~h}$ ). The increase in aerobic stability with increasing rust infestation was more pronounced in INOC than CON silages (rust $\times$ inoculant interaction, $P=0.01$ ), further justifying inoculation of the silages.

Aflatoxin was only detected in the CON HR silage (rust $\times$ inoculant interaction, $P=0.10$; Table 4 ) and the level $(5.2 \mathrm{mg} / \mathrm{kg})$ was above the action level of $20 \mu \mathrm{g} /$ $\mathrm{kg}$ stipulated by the US Food and Drug Administration for dietary ingredients for dairy cattle. Consequently, the CON HR silage would be unsafe to feed. High levels of aflatoxin in corn silage are notable but not unique. González Pereyra et al. (2008) reported an aflatoxin concentration of $156 \mu \mathrm{g} / \mathrm{kg}$ in corn silage, yet silage is expected to have low concentrations of aflatoxin because the toxin is primarily produced by Aspergillus flavus and Aspergillus parasiticus, which have low tolerance for the anaerobic conditions and low $\mathrm{pH}$ in silage (Holmquist et al., 1983). However, the latter factors do not prevent the survival of these organisms in silage. Garon et al. (2006) successfully isolated A. parasiticus from corn silage samples with a high aflatoxin concentration $(34 \mu \mathrm{g} / \mathrm{kg})$.

That no toxin was found in the inoculated HR silage suggests that inoculation prevented accumulation

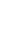

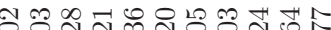

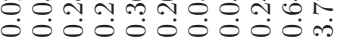


Table 4. Effect of rust infestation level and inoculant application on mycotoxin concentration of corn silage $(\mathrm{mg} / \mathrm{kg} \text { of } \mathrm{DM})^{1}$

\begin{tabular}{|c|c|c|c|c|c|c|c|c|c|c|}
\hline Item & \multicolumn{3}{|c|}{ Control } & \multicolumn{3}{|c|}{ Inoculant } & SEM & \multicolumn{3}{|c|}{$P$-value } \\
\hline Zearalenone & 0.64 & 0.0 & 0.0 & 0.471 & 0.0 & 0.0 & 0.080 & 0.303 & $<0.001$ & 0.303 \\
\hline Deoxynivalenol & 0.00 & 0.0 & 0.00 & 0.00 & 0.0 & 0.00 & 0.00 & $\mathrm{NA}^{2}$ & NA & NA \\
\hline Fumonisin & 0.00 & 0.0 & 0.00 & 0.00 & 0.0 & 0.00 & 0.00 & NA & NA & NA \\
\hline
\end{tabular}

${ }^{1}$ Control $=$ no inoculant added; inoculant $=1 \times 10^{5}$ cfu of Pediococcus pentosaceus and $4 \times 10^{5}$ of Lactobacillus buchneri; NR $=$ no-rust level; $\mathrm{MR}=$ medium rust level; $\mathrm{HR}=$ high rust level.

${ }^{2} \mathrm{NA}=$ not applicable.

of the toxin in silage. Future research should validate this finding and determine effects of rust infestation on populations of $A$. parasiticus and A. flavus on corn forages before and after ensiling.

No deoxynivalenol or fumonisin was detected in the silages. However, unlike rust-infested silages, CON and INOC NR silages had high concentrations of zearalenone (0.65 vs. $0.47 \mathrm{mg} / \mathrm{kg}$, respectively). The Food and Drug Administration (Silver Spring, MD) does not have action advisory levels for zearalenone; however, the concentrations of zearalenone in this study were below the guidance level $(2,000 \mu \mathrm{g} / \mathrm{kg})$ stipulated by the European Commission legislation (European Commission, 2006). The presence of zearalenone in the CON NR silage indicates that summer or second planting corn silage in the Southeast could be infested with this mycotoxin, possibly because of the hot, humid conditions.

No data was found in the literature on how inoculation affects the quality of disease-infested silage. However, effects of bacterial inoculation on the quality of ensiled healthy corn plants are well documented (Pedroso et al., 2010; Schmidt and Kung 2010; Arriola et al., 2011). Huisden et al. (2009) reported that the aerobic stability of corn silage was increased by the same inoculant used in this study (LB500; 143 vs. 389 h). Schmidt and Kung (2010) demonstrated that L. buchneri alone or in combination with $P$. pentosaceus increased the concentration of acetate, which decreased the population of spoilage fungi and increased aerobic stability of corn silage. In this study, mean concentrations of antifungal acids (acetate and butyrate) were increased by inoculation and, hence, mean aerobic stability was increased. The inoculated HR silage had the greatest acetate concentration, the lowest mold counts, and the best aerobic stability. These results reflect the ability of L. buchneri in the inoculant to synthesize the antifungal organic acid, acetate, by using lactate as a substrate (Oude Elferink et al., 2001).

\section{CONCLUSIONS}

Increasing levels of rust infestation were associated with reduced nutritive value and poorer fermentation of corn silage. Silages with the highest level of rust infestation had an aflatoxin concentration that exceeded the Food and Drug Administration action level for livestock feeds, which implies that they were unsafe to feed. Inoculation with the dual-purpose inoculant decreased most negative effects of rust infestation on the nutritive value and fermentation of the silage and prevented accumulation of aflatoxin in the highly infested silage.

\section{ACKNOWLEDGMENTS}

The authors gratefully acknowledge funding for this project from Lallemand Animal Nutrition (Milwaukee, WI).

\section{REFERENCES}

AOAC (Association of Official Analytical Chemists). 1985. Official Methods of Analysis. 14th ed. AOAC, Washington, DC.

Arriola, K. G., S. C. Kim, and A. T. Adesogan. 2011. Effect of applying inoculants with heterolactic or homolactic and heterolactic bacteria on the fermentation and quality of corn silage. J. Dairy Sci. 94:1511-1516

Dimmock, J. P. R. E., and M. J. Gooding. 2002. The influence of foliar diseases, and their control by fungicides on the protein concentration in wheat grain: A review. J. Agric. Sci. 138:349-366.

European Commission. 2006. Commission recommendation of $17 \mathrm{Au}-$ gust 2006 on the presence of deoxynivalenol, zearalenone, ochratoxin A, T-2 and HT-2 and fumonisins in products intended for animal feeding. Off. J. Eur. Union 229:7-8.

Garon, D., E. Richard, L. Sage, V. Bouchart, D. Pottier, and P. Lebailly. 2006. Mycoflora and multimycotoxin detection in corn silage: Experimental study. J. Agric. Food Chem. 54:3479-3484.

González Pereyra, M. L., V. A. Alonso, R. Sager, M. B. Morlaco, C. E. Magnoli, A. L. Astoreca, C. A. R. Rosa, S. M. Chiacchiera, M. Dalcero, and L. R. Cavaglieri. 2008. Fungi and selected mycotoxins from pre- and postfermented corn silage. J. Appl. Microbiol. 104:1034-1041.

Hammerschmidt, R. 1984. Rapid deposition of lignin in potato tuber tissue as a response to non-pathogenic fungi on potato. Physiol. Plant Pathol. 24:33-42. 
Holmquist, G. U., H. W. Walker, and H. M. Stahr. 1983. Influence of temperature, $\mathrm{pH}$, water activity and antifungal agents on growth of Aspergillus flavus and A. parasiticus. J. Food Sci. 48:778-782.

Huisden, C. M., A. T. Adesogan, S. C. Kim, and T. Ososanya. 2009. Effect of applying molasses or inoculants containing homofermentative or heterofermentative bacteria at two rates on the fermentation and aerobic stability of corn silage. J. Dairy Sci. 92:690-697.

Johnson, J. C., R. N. Gates, G. L. Newton, J. P. Wilson, L. D. Chandler, and P. R. Utley. 1997. Yield, composition, and in vitro digestibility of temperate and tropical corn hybrids grown as silage crops planted in summer. J. Dairy Sci. 80:550-557.

Kang, T. W., A. T. Adesogan, S. C. Kim, and S. S. Lee. 2009. Effects of an esterase-producing inoculant on fermentation, aerobic stability, and neutral detergent fiber digestibility of corn silage. J. Dairy Sci. 92:732-738.

Kim, S. C., and A. T. Adesogan. 2006. Influence of ensiling temperature, simulated rainfall, and delayed sealing on fermentation characteristics and aerobic stability of corn silage. J. Dairy Sci. 89:3122-3132.

Kung, L., M. R. Stokes, and C. J. Lin. 2003. Silage additives. Pages 305-360 in Silage Science and Technology. D. R. Buxton, R. E. Muck, and J. H. Harrison, ed. American Society of AgronomyCrop Science Society of America-Soil Science Society of America (ASA-CSSA-SSSA), Madison, WI.

Liu, Y., and J. Wang. 1999. Southern corn rust occurred in Hebei Province in 1998. Plant Protection 25:53-58.

Lucas, J. A. 1998. Plant Pathology and Pathogens. 3rd ed. Blackwell Science, Oxford, UK.

Mallmann, C. A., P. Dilkin, A. O. Mallmann, and D. Tyska. 2009 Mycotoxin: Impacts and control strategies. Pages 269-280 in Proc. Int. Symp. Forage Quality Conservation. M. Zopollato, G. B. Muraro, and L. G. Nussio, ed. Fundação de Estudos Agrários Luiz de Queiroz (FEALQ), Piracicaba, SP, Brazil.

Manners, J. M., D. J. Maclean, and K. J. Scott. 1982. Pathways of glucose assimilation in Puccinia graminis. J. Gen. Microbiol. $128: 2621-2630$.

McDonald, P., N. Henderson, and S. Heron. 1991. The Biochemistry of Silage. 2nd ed. Chalcombe Publications, Bucks, UK.
Oude Elferink, S. J. W. H., J. Krooneman, J. C. Gottschal, S. F. Spoelstra, F. Faber, and F. Driehuis. 2001. Anaerobic conversion of lactic acid to acetic acid and 1,2-propanediol by Lactobacillus buchneri. Appl. Environ. Microbiol. 67:125-132.

Pedroso, A. F., A. T. Adesogan, O. C. M. Queiroz, and S. K. Williams. 2010. Control of Escherichia coli O157:H7 in corn silage with or without various inoculants: Efficacy and mode of action. J. Dairy Sci. 93:1098-1104.

Potter, L. R. 1987. Effect of crown rust on regrowth, competitive ability and nutritional quality of perennial and Italian ryegrasses. Plant Pathol. 36:455-461.

Raid, R. N., S. P. Pennypacker, and R. E. Stevenson. 1988. Characterization of Puccinia polysora epidemics in Pennsylvania and Maryland. Phytopathology 78:579-585.

Rhind, D., J. M. Waterson, and F. C. Deighton. 1952. Occurrence of Puccinia polysora Underw. in West Africa. Nature 169:631-632.

Ride, J. P. 1978. The role of cell wall alterations in resistance to fungi. Ann. Appl. Biol. 89:302-306.

Rodriguez-Ardon, R., G. E. Scott, and S. B. King. 1980. Maize yield losses caused by southern maize rust. Crop Sci. 20:812-814

Schmidt, R. J., and L. Kung Jr. 2010. The effects of Lactobacillus buchneri with or without a homolactic bacterium on the fermentation and aerobic stability of corn silages made at different locations. J. Dairy Sci. 93:1616-1624.

Scott, P. M., J. W. Lawrence, and W. van Walbeek. 1970. Detection of mycotoxins by thin-layer chromatography: Application to screening of fungi extracts. Appl. Microbiol. 20:839-842.

Van Soest, P. J., J. B. Robertson, and B. A. Lewis. 1991. Methods for dietary fiber, neutral detergent fiber and nonstarch polysaccharides in relation to animal nutrition. J. Dairy Sci. 74:3583-3597.

Van Soest, P. J., R. H. Wine, and L. A. Moore. 1966. Estimation of the free digestibility of forages by the in vitro digestion of cell walls. Page 438 in Proc. 10th Intl. Grassl. Congr., Helsinki, Finland.

Wilson, J. P., R. N. Gates, and W. W. Hanna. 1991. Effect of rust on yield and digestibility of pearl millet forage. Phytopathology 81:233-236. 